\title{
Indian Brachytherapy Society Guidelines for radiotherapeutic management of cervical cancer with special emphasis on high-dose-rate brachytherapy
}

\author{
Umesh Mahantshetty, MD', Shivakumar Gudi, MD', Roshni Singh, MD', Ajay Sasidharan, MD', \\ Supriya (Chopra) Sastri, MD', Lavanya Gurram, MD', Dayanand Sharma, MD², Selvaluxmy Ganeshrajah, MD³. \\ Janaki MG, MD ${ }^{4}$, Dinesh Badakh, MD ${ }^{5}$, Abhishek Basu, MD ${ }^{6}$, Francis James, $M D^{7}$, Jamema V Swamidas, PhD ${ }^{8}$, \\ Thayalan Kuppuswamy, PhD?', Rajendra Bhalavat, MDl0 \\ 'Department of Radiation Oncology, Tata Memorial Centre, Homi Bhabha National Institute, Mumbai, India, ${ }^{2}$ Department of Radiation \\ Oncology, All India Institute of Medical Sciences, New Delhi, India, ${ }^{3}$ Department of Gynecology Oncology. Cancer Institute (WIA), Chennai \\ India, ${ }^{4}$ Department of Radiation Oncology, M.S. Ramaiah Memorial Hospital, Bangalore, India, ${ }^{5}$ Department of Radiation Oncology. \\ Siddhivinayak Cancer Hospital, Miraj, India, 'Department of Radiation Oncology, R.G. Kar Medical College and Hospital, Kolkata. \\ India, ${ }^{7}$ Department of Radiation Oncology, Regional Cancer Centre, Thiruvananthapuram, India, ${ }^{8}$ Department of Medical Physics, Tata \\ Memorial Centre, Homi Bhabha National Institute, Mumbai, India, ${ }^{9}$ Medical Physics Division, Dr. Kamakshi Memorial Hospital, Chennai, India, \\ ${ }^{10}$ Department of Radiation Oncology, Jupiter Hospital, Mumbai, India
}

\begin{abstract}
Brachytherapy (BT) for locally advanced cervical cancer is vital for optimal outcomes. There is heterogeneity in brachytherapy treatment practice for cervical cancer across India. In an attempt to standardize various processes involved in cervical cancer brachytherapy, the expert members of the Indian Brachytherapy Society (IBS) developed a document related to radiation therapy treatment of cervical cancer with special emphasis on brachytherapy. The guidelines are based on high quality clinical evidence, expert opinion and consensus wherever evidence was lacking. The document provides a guide for external beam radiation and details of all the processes involved in high-dose-rate (HDR) brachytherapy including patient selection, preparation, principles and technique of BT applications, target and normal tissue definition, dose prescriptions, BT planning, reporting parameters, common complications of BT and their management, scope for research, etc. In summary, we present here practical tips and tricks, recording and reporting of cervical cancer brachytherapy, which can be implemented in various clinical environments and forms the basis of this report.
\end{abstract}

Key words: cervical cancer, brachytherapy, Indian Brachytherapy Society, high-dose-rate.

\section{Purpose}

Cervical cancer is the second most common malignancy, constituting approximately $17 \%$ of worldwide cancer incidence and $8.4 \%$ of overall cancer incidence in India [1]. Moreover, more than two thirds of them present at advanced stage [2].

Radio(chemo)therapy forms the primary curative treatment modality for locally advanced cervical cancer [3]. Radiotherapy consists of external beam radiotherapy (EBRT) with concurrent weekly platinum-based radiosensitizing chemotherapy and brachytherapy (BT). BT, being a highly conformal form of radiation technique, allows delivery of high doses to the tumor, and is the cornerstone for optimal clinical outcomes and toxicities.

There are various guidelines for treatment of cervical cancer including brachytherapy [4,5]. These guidelines are primarily designed and applicable for the western world and are of limited value in low and middle-income countries (LMICs) including India. Moreover, LMICs have a unique ethnic and cultural background, disease patterns, health care systems and access to treatment facilities [6]. Also, inadvertent/suboptimal hysterectomy for benign causes and incidental diagnosis of cervical cancer is not uncommon. These situations pose a major challenge for further management. The treatment practic-
Address for correspondence: Prof. Umesh Mahantshetty, Department of Radiation Oncology, 1123, $11^{\text {th }}$ floor, Homi Bhabha Block, Tata Memorial Hospital, Homi Bhabha National Institute,

Mumbai-400012, Maharashtra, India, phone: +91-22-24177168, 凶e-mail: mahantshettyum@tmc.gov.in
Received: 04.06 .2019

Accepted: 30.07 .2019

Published: 29.08.2019 
es are generally influenced by regional differences in cultural and socioeconomic factors, availability of resources and expertise, improvements in knowledge and technology, etc., resulting in highly heterogeneous patterns of care $[7,8]$. In an attempt to streamline further management and improve the patient care with an intention to improve the clinical outcome, we proposed to work on guidelines to suit these clinical situations. The majority of the centers in India, currently, practice high-dose-rate (HDR) brachytherapy for cervical cancers [9]. We propose here the guidelines for HDR brachytherapy for cervical cancers.

\section{Material and methods}

A panel of Indian Brachytherapy Society members with a special interest in the management of cervical cancer and brachytherapy was constituted. All experts are from major institutions with a relatively large number of cervical cancer patients (> 50-100 per year) being treated and involved in establishing standards for radiotherapeutic management of cervical cancers in India. The scope of this report was to review, discuss and propose some practical recommendations to ensure minimum standards of radiotherapy with special emphasis on brachytherapy treatment for cervical cancers in India. The process involved defining important steps, thorough literature review and discussion, and guidelines constituted based on available evidence and its relevance to Indian settings. Consensus recommendations were formed for the spectrum of clinical practice. Guidelines were also formed for the sections with limited literature based on consensus recommendations provided by the expert panel. The scope for research in sections with limited literature was also identified and mentioned in the respective section when applicable.

\section{Results}

Below are the guidelines and recommendations for cervical cancer management with special emphasis on brachytherapy.

\section{Pre-treatment and staging workup}

Once the diagnosis of cervical cancer is confirmed with histopathological evaluation, all patients should undergo

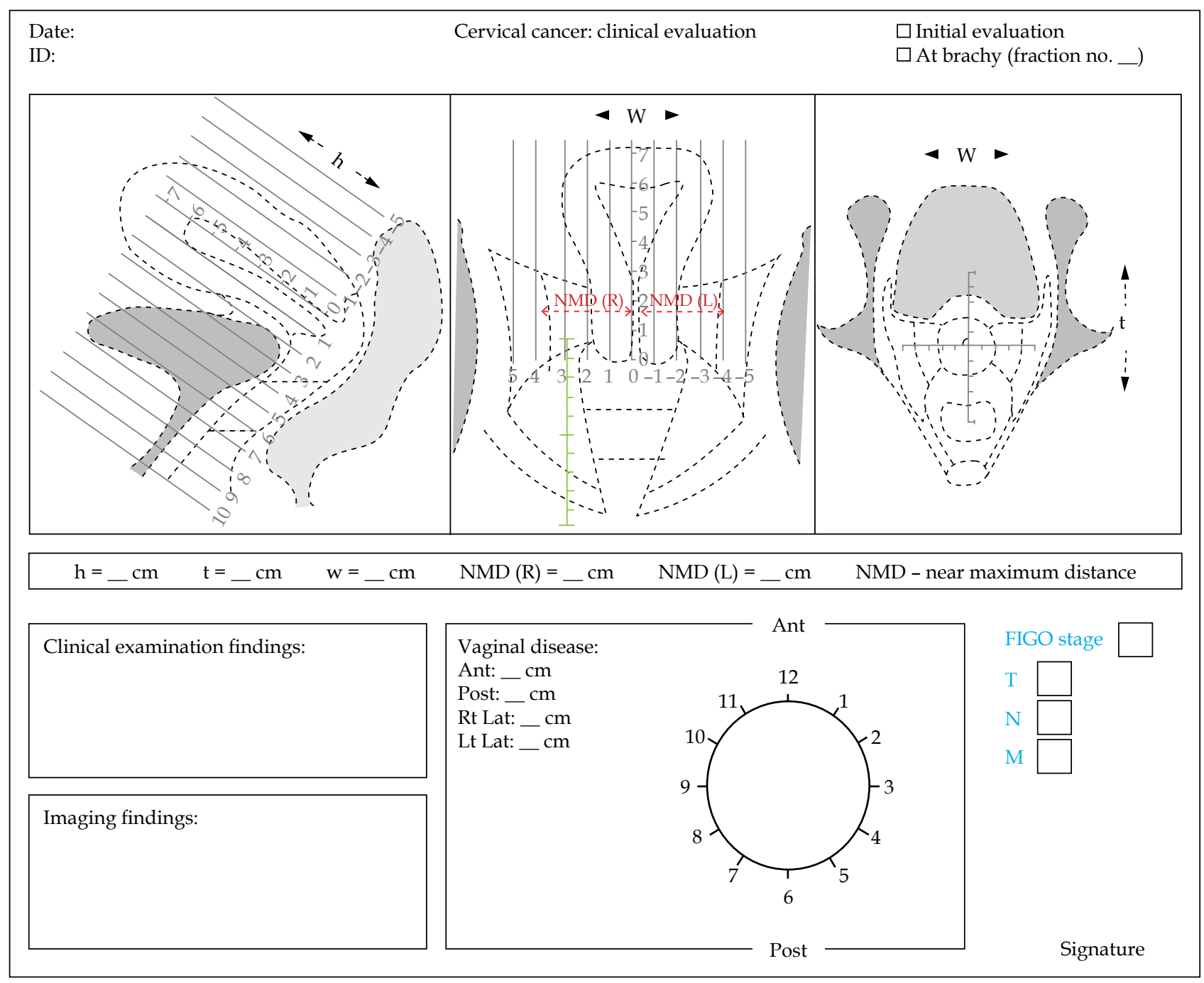

Fig. 1. Clinical drawing for 3 dimensional documentation of disease 
a complete blood count, renal function tests, liver functions, coagulation parameters, and chest radiograph as part of the assessment of general status and fitness for therapy.

Thorough clinical examination, under anesthesia if warranted, for mapping and proper documentation of local disease topography should be mandatory. Figure 1 and 2 show an example of a clinical drawing which can be utilized for disease mapping and objective documentation in terms of extent of disease involving cervical lips, vagina, parametrium, etc., with different color codes/patterns and measurements in various directions. Apart from conventional dimensions (height, width and thickness) the width in relation to the central canal/external os is introduced as the near maximum distance (NMD). It is the distance between the external os (surrogate for cervical canal) and the lateral most extent of parametrial disease on each side (right and left NMD) which can be documented clinically/clinico-radiologically. This represents the symmetry of disease in relation to the cervical canal and assists in deciding the brachytherapy application more efficiently.

The clinical drawing has been adopted and modified based on the European study on magnetic resonance image-based adaptive brachytherapy in locally advanced cervical cancers (EMBRACE) research protocol (www. embracestudy.dk), Gynaecology group - Groupe Européen de Curiethérapie European Society for Therapeutic radiology and oncology (Gyn GEC-ESTRO) guidelines and International Commission on Radiation Units and measurements report number 89 (ICRU 89) recommendations [10,11,12]. This drawing should be utilized for documentation of disease at diagnosis, and at the time of each brachytherapy session.

Cystoscopy and procto-sigmoidoscopy with or without biopsy should be carried out if clinically indicated.

Magnetic resonance imaging (MRI) is the gold standard imaging for assessment of local disease extent (e.g. parametrial and uterine extent). Trans-rectal ultrasonography by an experienced radiologist may be useful in detection of parametrial invasion.

For nodal disease, cross sectional imaging of the abdomen and pelvis, either MRI or computed tomography (CT) is recommended for locally advanced disease to assess pelvic and para-aortic nodal involvement. However, positron emission tomography-computed tomography (PET-CT) has higher sensitivity and specificity for detection of pelvic and para-aortic nodes as compared to CT/MR

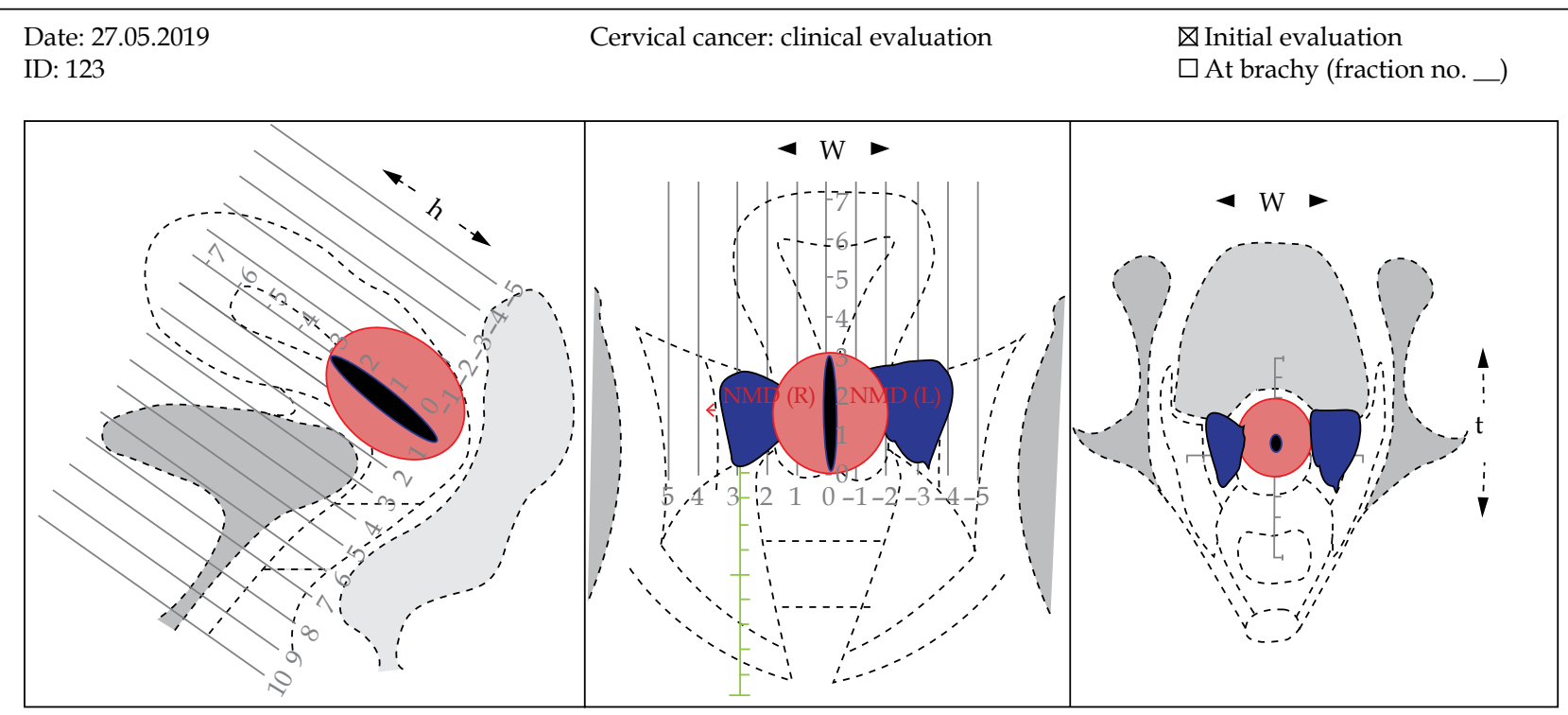

$\mathrm{h}=\underline{3} \mathrm{~cm} \quad \mathrm{t}=\underline{3} \mathrm{~cm} \quad \mathrm{w}=\underline{7} \mathrm{~cm} \quad \mathrm{NMD}(\mathrm{R})=\underline{3} \mathrm{~cm} \quad$ NMD $(\mathrm{L})=\underline{4} \mathrm{~cm} \quad$ NMD - near maximum distance

Clinical examination findings:

$3 \times 3 \times 7 \mathrm{~cm}$ infiltrative growth involving both lips of cervix, bilateral medial parametrium (left > right) vagina free, rectal mucosa free

Imaging findings:

CECT scan - heterogeneously enhancing le sion in uterine cervix, enlarged left internal iliac node $1.5 \mathrm{~cm} \times 1.5 \mathrm{~cm}$. No distant mets

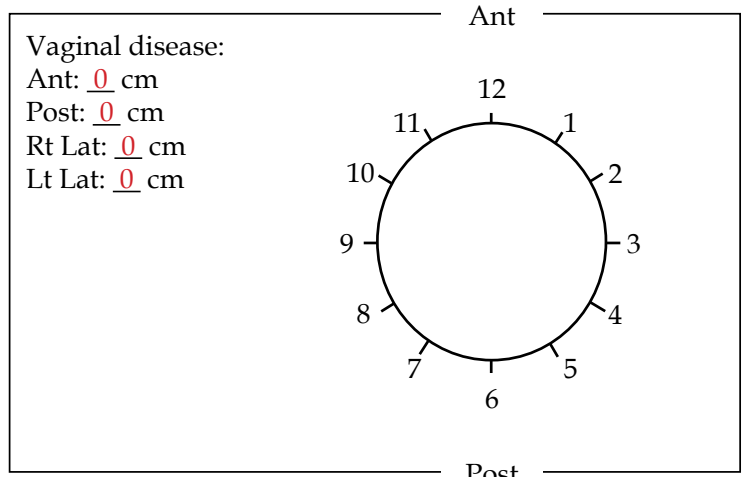

FIGO stage IIb

$\mathrm{T} 2 \mathrm{~b}$

N 1

$\mathrm{M} 0$

Fig. 2. An example of clinical drawing for 3 dimensional documentation of disease 
although the evidence is evolving [13]. Hence, PET-CT may be considered for pelvic and para-aortic nodal assessment subject to availability and affordability. Ultrasonography by an experienced radiologist can be an effective alternative to identify gross pelvic and paraaortic nodes and the status of the kidney in settings where cross sectional imaging is not feasible/available.

The final clinical International Federation of Gynecology and Obstetrics (FIGO) staging, after evaluation of local disease nodal disease, kidney status, and rectal/ bladder mucosal invasion, should be documented. In addition to FIGO, TNM stage is encouraged for better understanding of primary and nodal disease.

\section{External beam radiotherapy}

The goal of external beam radiotherapy (EBRT) is to deliver a dose of 45-50 Gy at 1.8-2.0 Gy per fraction to gross disease and the potential subclinical disease including pelvic lymph nodal with or without para-aortic nodal regions. Four-field box technique (conventional or 3D conformal radiotherapy) to adequately cover the target is recommended. An additional nodal and/or parametrial boost can be considered when indicated, preferably with newer delivery techniques. When intensity-modulated radiation therapy (IMRT) technique is used in cases of an intact uterus, it should be combined with a strict image guidance protocol to account for organ motion.

\section{Chemotherapy}

Concurrent weekly cisplatin acts as radio sensitizer and has shown overall survival benefit [3]. Chemotherapy should preferably start on day 1 or 2 of EBRT and at least 5 cycles should be delivered [14]. Cisplatin given $\left(40 \mathrm{mg} / \mathrm{m}^{2}\right)$ weekly along with adequate hydration and antiemetics, after ensuring adequate creatinine clearance and hematologic parameters, is the drug of choice. Patients not suitable for concomitant cisplatin chemotherapy should be evaluated for alternatives including carboplatin, 5-fluorouracil, etc. by a medical oncologist although the data on their use are limited. Alternatively, patients may be offered radiation therapy alone.

\section{Brachytherapy}

Brachytherapy should be an integral part of curative radiotherapy treatment. Brachytherapy significantly improves survival as compared to any alternative treatments $[15,16]$.

\section{Patient eligibility}

Every attempt should be made to perform the BT application and treatment. In patients where BT is not feasible, EBRT boost preferably with highly conformal techniques (IMRT/stereotactic RT) may be considered after appropriate counseling regarding inferior outcomes [17].

\section{Patient preparation and counseling}

The patient has to be explained about the procedure including risks and benefits involved, emphasizing the need for brachytherapy for an optimal outcome. The patient should be counseled about possible adverse events. Informed consent should be obtained prior to the procedure.

Patient preparation for BT includes:

- preparation of skin and perineum including shaving and antiseptic vaginal douches,

- bowel preparation to ensure the recto-sigmoid is empty,

- appropriate management of co-morbidities,

- use of low-molecular-weight heparin (LMWH) once per day or low-dose unfractionated heparin (UFH) three times per day may be considered to prevent postoperative venous thromboembolism in high risk patients [18].

\section{Anesthesia}

Every BT application should preferably be performed under anesthesia. Anesthesia allows cervical canal dilatation and adequate relaxation of the pelvic floor and vaginal muscles for adequate vaginal packing and a reproducible brachytherapy application at every fraction [19]. General and spinal anesthesia are equally effective. A patient with high risk features and not suitable for general/spinal anesthesia or in centers with limited access to anesthesia facilities, conscious sedation (e.g. with fentan$\mathrm{yl}$ with/without midazolam) or para-cervical block may be considered $[20,21]$.

\section{Principles and technique of brachytherapy application}

A thorough pelvic examination must be done to assess and document the extent of residual disease and vaginal capacity to decide on the optimum size of the vaginal ovoids/ring/cylinders. This step is extremely important as this guides the selection of appropriate BT application technique, which depends on the topography of the residual disease at the time of BT.

To guide for appropriate BT technique, the topography of residual disease at the time of BT may be classified into the following categories:

- In patients with intact uterus:

- no residual disease,

- residual disease limited to cervix,

- residual disease at cervix limited to medial parametrium and/or upper vagina,

- residual disease extending into distal parametrium and/or lower vagina;

- In post-hysterectomy patients with vault disease, the residual disease at the time of BT can be classified into:

- no residual disease,

- residual disease confined to central vault,

- residual disease at vault extending into paracolpos/ parametrial tissue.

Depending on the categories defined above, appropriate BT techniques may be utilized which may be categorized into:

- intracavitary brachytherapy (ICBT),

- combined intracavitary and interstitial brachytherapy (ICIS),

- interstitial brachytherapy (ISBT). 
Various commercially available BT applicators and their physical and dosimetric properties for different BT techniques are given in Table 1 (Figure 3 ).

\section{Intracavitary brachytherapy}

Intracavitary brachytherapy is recommended if there is no residual disease, or residual disease at the cervix or limited to the medial parametrium and/or upper vagina. It primarily consists of placement of an applicator in uterine and vaginal cavities in the vicinity of target tissues (residual disease, uterus, parametrium, adjacent vaginal mucosa) by using uterine tandem and various vaginal source carriers such as ring/ovoids/cylinders. The use of vaginal applicators depends on the residual disease in the vagina; the upper vagina is usually well covered with ring/ovoid systems and for extensive vaginal residual disease beyond the upper vagina, vaginal cylinders are preferred.

The general principles of standard ICBT procedures are as follows:

The patient is positioned in lithotomy position followed by antiseptic painting and draping. The bladder is catheterized using a Foley catheter and a Foley bulb is instilled with 7 cc of radio-opaque dye if planned for radio-

Table 1. Brachytherapy applicators used for treatment of gynecological cancers Intracavitary brachytherapy (ICBT) applicators

\begin{tabular}{|c|c|}
\hline $\begin{array}{l}\text { Tandem and ovoid (TO) or Fletcher suit (FS) } \\
\text { type applicator ICBT }\end{array}$ & $\begin{array}{l}\text { Consists of uterine tube (central tandem) and } 2 \text { colpostats. Various angles of central } \\
\text { tandems and various sizes of colpostats are commercially available. It is a semi-fixed } \\
\text { applicator made of stainless steel or CT/MR compatible acrylic material or titanium } \\
\text { alloy } \\
\text { It is one of the most commonly used applicators, designed to deliver adequate dos- } \\
\text { es to uterus/cervix, upper vagina }(2-2.5 \mathrm{~cm}) \text { and medial parametrium by a standard } \\
\text { pear-shaped dose distribution }\end{array}$ \\
\hline Tandem and ring (TR) applicator - ICBT & $\begin{array}{l}\text { Consists of uterine tube and a ring as vaginal source carrier. It is a fixed geometry } \\
\text { stainless steel or CT/MRI compatible applicator and has similar dose distribution } \\
\text { properties as those of the TO applicator. The ring provides an additional degree of } \\
\text { freedom to load the vaginal sources over the ovoids. However, there are no substan- } \\
\text { tial data to suggest the dosimetric difference between TO and ring applicator }\end{array}$ \\
\hline Tandem with vaginal cylinders - ICBT & $\begin{array}{l}\text { Consists of central tandem and vaginal cylinders available in various diameter sizes } \\
\text { Cylinders are used in cases of narrow conical vagina where ovoids/ring are difficult } \\
\text { to accommodate or in cases of residual disease extending beyond the upper vagina. } \\
\text { The dose distribution is cylindrical. As there is a single source channel, lateral throw } \\
\text { off of dose in to the parametrium is less as compared to ovoids/ring }\end{array}$ \\
\hline \multicolumn{2}{|l|}{ Intracavitary and interstitial (IC + IS) applicators } \\
\hline $\begin{array}{l}\text { TR with interstitial needles } \\
\text { (Vienna applicator) - IC + IS }\end{array}$ & $\begin{array}{l}\text { It is based on a MRI compatible tandem with ring with an array of holes in the sur- } \\
\text { face of the ring for insertion of needles/tubes into the medial parametrium. Hence it } \\
\text { provides a template at the level of the vaginal fornices to insert needles/tubes into } \\
\text { the parametrium. These needles when loaded improve the lateral dose throw off by } \\
\text { another } 1.5 \mathrm{~cm} \text { to treat additional parametrium [20] }\end{array}$ \\
\hline $\begin{array}{l}\text { TO with interstitial needles } \\
\text { (Utrecht applicator) - IC + IS }\end{array}$ & $\begin{array}{l}\text { On similar principles as the Vienna applicator for IC }+I S \text {, the Utrecht applicator has } \\
\text { holes in the ovoids to insert needles into the parametrium to improve coverage } \\
\text { beyond point } A\end{array}$ \\
\hline Venezia applicator & $\begin{array}{l}\text { Consists of central tandem, ovoids/two ring halves that can accommodate straight } \\
\text { or diverging interstitial parametrial needles and a detachable perineal template. The } \\
\text { applicator is designed for the treatment of advanced disease with involvement of lat- } \\
\text { eral parametrium with the modified ovoid/ring } 2 \text { halves system and/or lower vagina } \\
\text { or paracolpos with the perineal template }\end{array}$ \\
\hline \multicolumn{2}{|l|}{ Interstitial templates } \\
\hline Syed-Neblett GYN Template & $\begin{array}{l}\text { Consists of perineal template with provision for central vaginal cylinder and tan- } \\
\text { dem when required. The template provides an array of holes to insert needles/tubes } \\
\text { through the perineum in a butterfly shaped positions }\end{array}$ \\
\hline $\begin{array}{l}\text { Martinez Universal Perineal Interstitial } \\
\text { Template (MUPIT) }\end{array}$ & $\begin{array}{l}\text { The device consists of an acrylic perineal template with a predrilled array of holes to } \\
\text { guide passage of straight and divergent needles, and the cylindrical obturator. Num- } \\
\text { ber of needles, depth of insertion, angle and positions of needles determine the dose } \\
\text { distribution characteristics and can be used to treat the desired target area in the } \\
\text { pelvis. The needles can be secured for individual movements with the help of screws } \\
\text { and a reinforcement plate }\end{array}$ \\
\hline
\end{tabular}




\section{A}
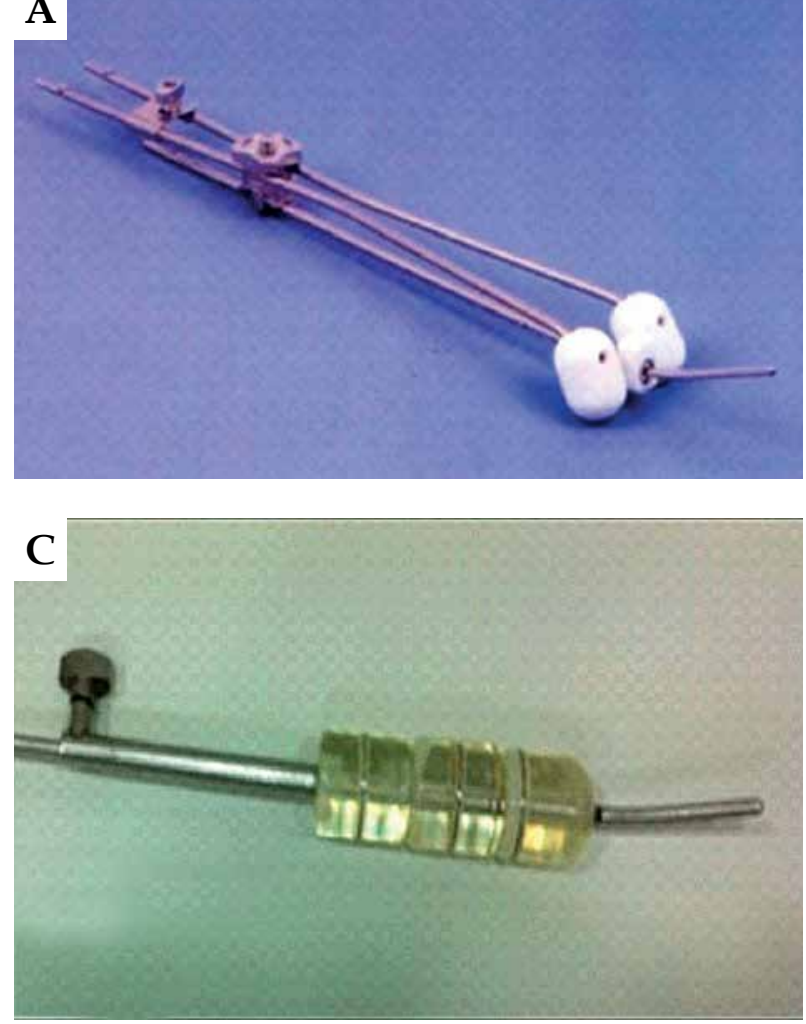

E

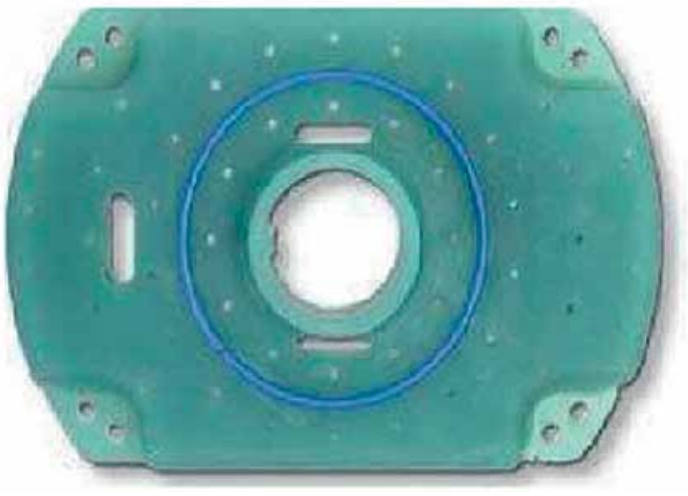

G

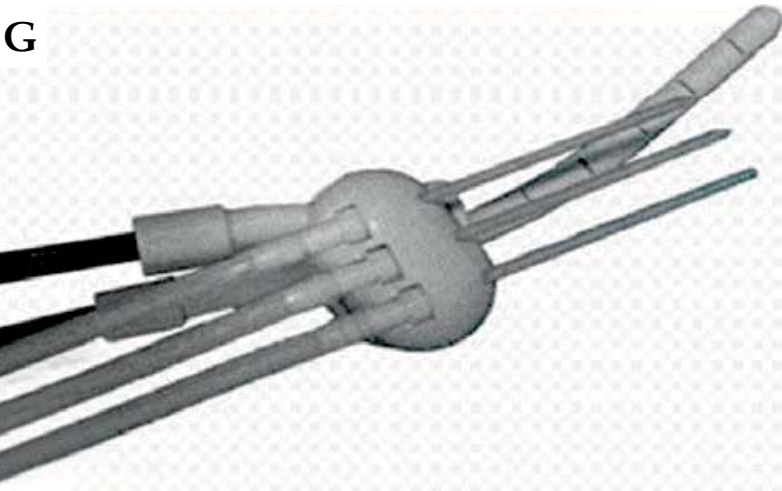

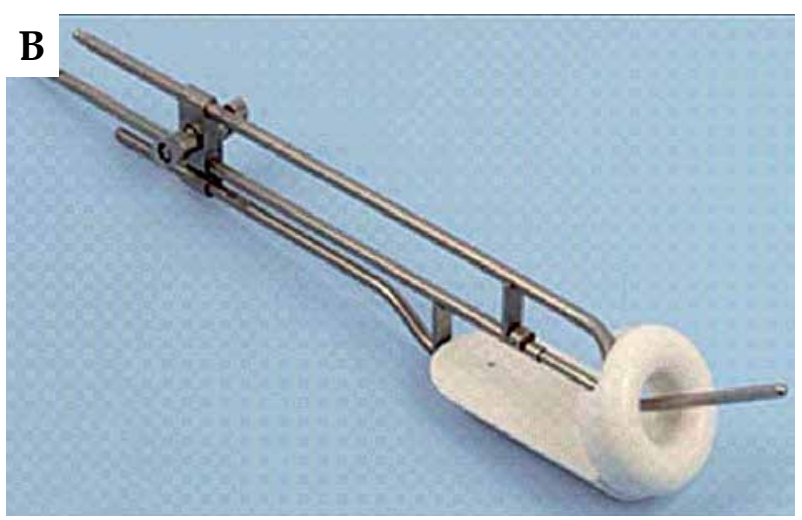
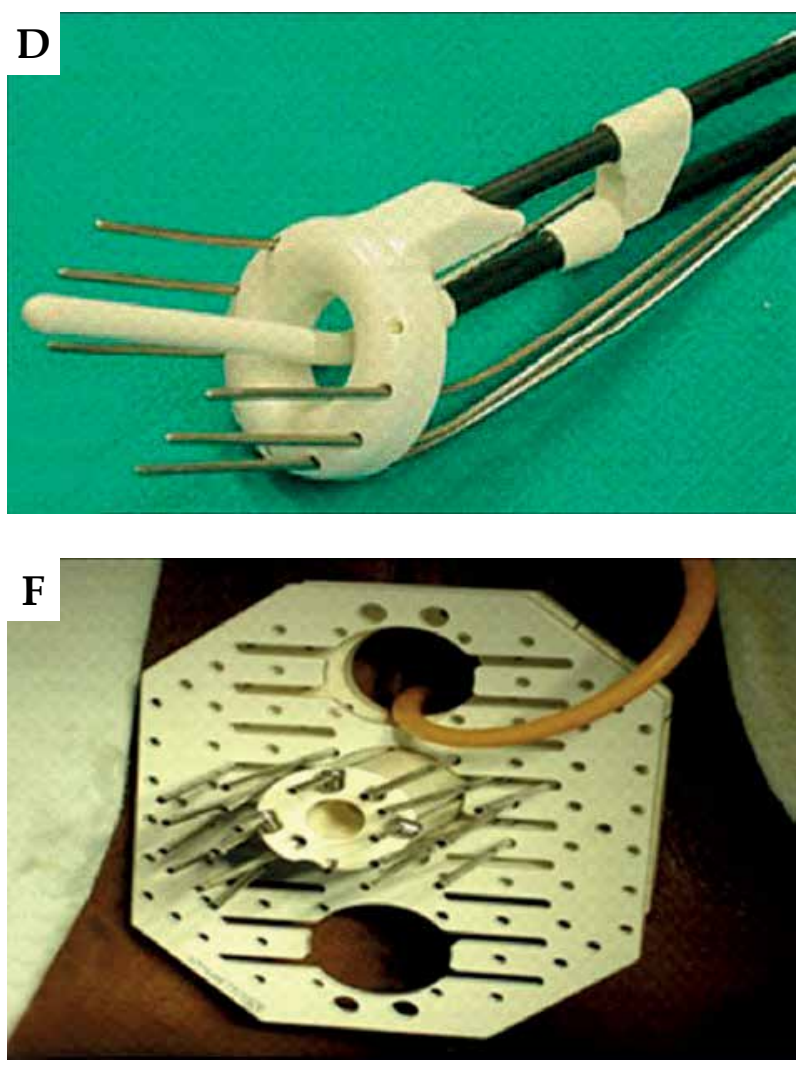

$\mathbf{H}$

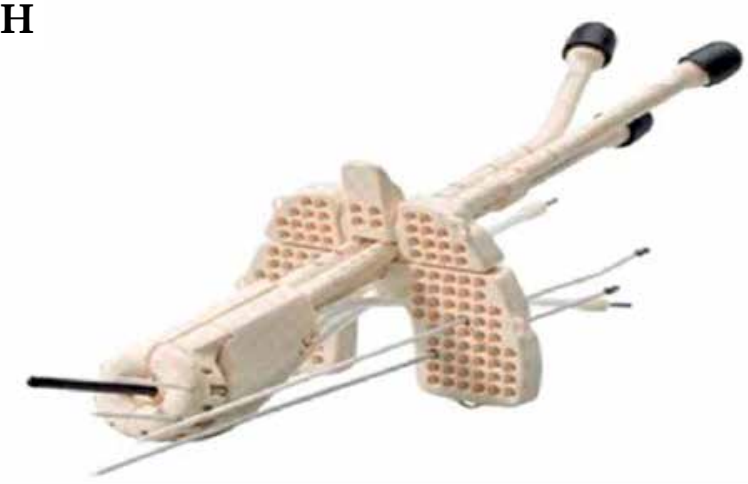

Fig. 3. Commonly used gynecological brachytherapy applicators for cancer of cervix. A) Fletcher Suit applicator; B) Tandem with ring; C) Tandem with cylinders; D) Vienna applicator; E) Syed-Neblett gynecological interstitial template; F) Martinez Universal Perineal Interstitial Template (MUPIT); G) Utrecht applicator; H) Venezia applicator 
graph-based dosimetry or normal saline if planned for CT/ MR-based dosimetry. The catheter should be pulled down so that the bulb rests against the trigone of the bladder and secured by fixing the Foley catheter to the inner thigh by a micropore. A fixed bladder protocol, which is reproducible and as mandated by the institution, should be chosen and followed. A thorough examination under anesthesia or sedation is done for disease mapping and documentation of dimensions should be done. The uterine cavity is sounded and a uterine tandem of appropriate length and angle with flange/stopper is inserted. It is recommended to use the guidance of real-time ultrasonography (with or without bladder filling) to ensure that the tandem is placed in the uterine cavity so as to avoid uterine perforations [22]. The cervical canal is appropriately dilated before tandem insertion. Optimum ovoid/ring size should be used without compromising vaginal packing. Adequate vaginal packing (radio-opaque gauze for conventional radiograph-based planning) is done anterior and posterior to the ovoid/ring in an attempt to push the rectum and bladder away from the high dose region. The rest of the vaginal packing distally is done to stabilize the applicator geometry. Care should be taken not to extend the vaginal packing cranial to the ovoid/ring. Rectal separators can be used alternatively for rectal packing. The packing should be done appropriately and carefully to avoid any disturbance in the position and geometry of the applicator.

If the upper vagina is narrow and conical, tandem with single ovoid BT application can be done [23]. However, if the residual disease in the vagina extends beyond the upper vagina, tandem-cylinder application or an ovoid applicator with a vaginal cap is preferred. The major limitation of tandem-cylinder ICBT application is compromise in the dose to the medial parametrium by virtue of poor lateral throw off of the isodose distribution and higher doses to organs at risk. The applicator should be secured with a T-bandage (Figure 4).

\section{Combined intracavitary and interstitial brachytherapy}

Combined intracavitary and interstitial brachytherapy is recommended if the residual disease at the cervix extends into the parametrium beyond the medial third at the time of BT. The principle of ICIS application includes insertion of interstitial needles/tubes in addition to the standard ICBT procedure. The needles/tubes are inserted through the array of holes in the ovoids/ring into the medial parametrium, in parallel direction to the tandem [24]. If the residual disease extends into the lateral parametrium, then insertion of additional oblique needles/tubes in the lateral parametrium can be attempted.

Usually $4 / 5 \mathrm{~cm}$ length of needle is inserted into the parametrium from the surface of the vaginal applicators (ovoid/ring). Commonly used applicators include the Vienna applicator, Utrecht applicator, Venezia applicator or Tandem with perineal template (Syed-Neblett or MUPIT). Patient preparation and painting/draping and the catheterization procedure are similar as described in ICBT. After placement of the central tandem in the uterine cavity and confirmation using US, the ring/ovoids with the needles/tube preloaded is locked with the tandem. The interstitial needles in desired positions are inserted to a depth of around $4-5 \mathrm{~cm}$ from the surface of the ring/ ovoid. Needle channels should be numbered preferably in clock-wise direction. Vaginal packing is done as applicable in order to fix the applicator and needle system and a rectal tube is inserted to keep the rectum collapsed (Figure 3).

\section{Interstitial brachytherapy}

Interstitial brachytherapy is recommended in vault cancers with residual disease at vault with significant disease in the parametrium at the time of BT [25]. Commonly used templates for ISBT are MUPIT and Syed-Neblett or customized templates. Newer MRI compatible templates (e.g. Benidorm template) are also used if MRI-based planning is considered [26]. The principles of the ISBT procedure include thorough pelvic examination under anesthesia and implantation of radio-opaque silver markers to mark the superior, central, and inferior extent of the residual disease whenever feasible. The length of the vagina is determined using the obturator. With the obturator in the vagina and the template against the perineum, stainless steel needles with
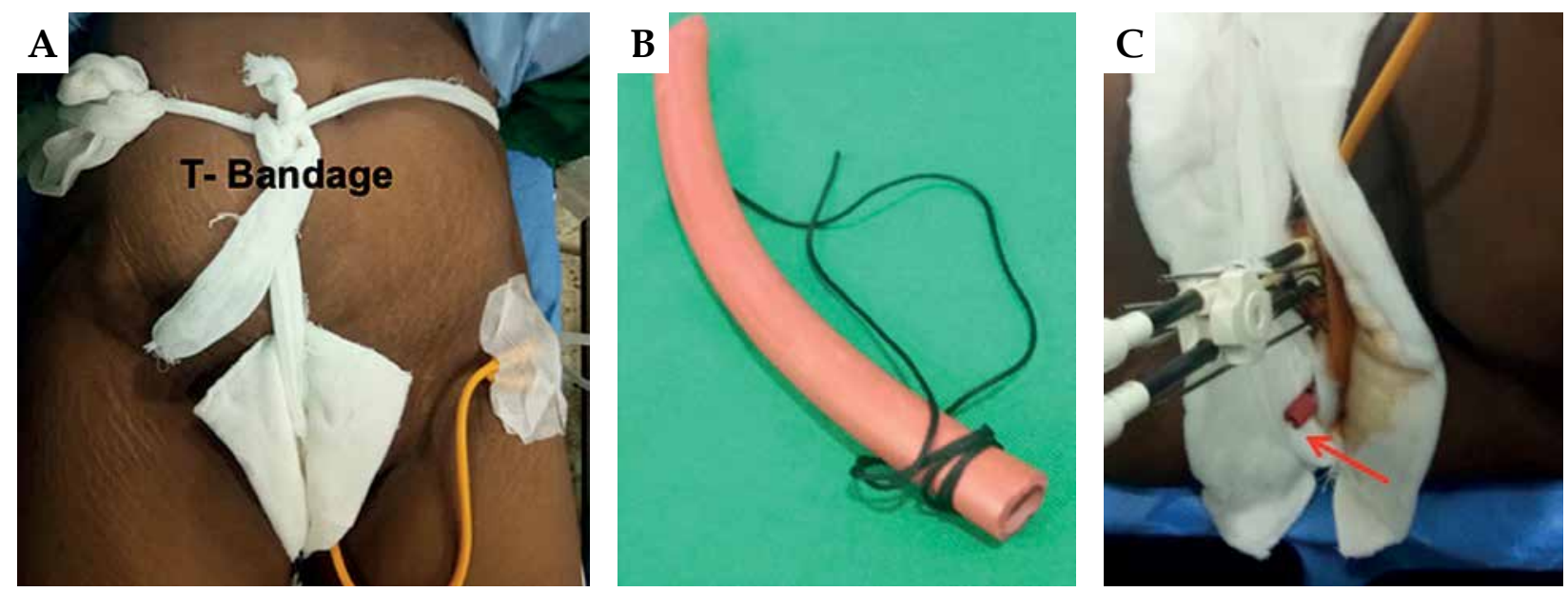

Fig. 4. Picture depicting $\mathrm{T}$ bandage (A), rectal tube (B) and rectal tube with applicator in situ (C) 
a trocar tip (18-20 cm length) are inserted through the perineum into the desired target adequately using an array of holes over the template. The number and position of the needles are according to the stipulated depth under digital rectal examination with or without transrectal ultrasound guidance. Digital rectal examination/ trans-rectal ultrasound is used to ensure that the needles are adequately placed in the desired target area and are away from the rectal mucosa. A rectal tube is placed into the recto-sigmoid to keep the rectum collapsed and continuously drain the mucous discharge throughout the treatment. All the needles are secured in between the two plates with fixation screws. The template assembly is fixed to the perineal skin by stitches at the four corners of the template. Adequate intra- and postoperative analgesia should be considered for all the brachytherapy application procedures.

\section{Imaging for treatment planning}

Imaging after placement of the applicator provides essential information regarding relative positions of the applicator with respect to target and normal structures and allows contouring of these structures and documentation of the doses received by the target (point A or high risk clinical target volume) and organs at risks (OAR). Use of imaging is mandatory for treatment planning. Orthogonal radiographs and cross sectional imaging (CT/MRI) are among the imaging modalities that have been widely used in planning for cervical cancer brachytherapy. There is accumulating evidence for the use of MR image-based brachytherapy with improved outcomes and hence it can be considered as the preferred method whenever available $[27,28]$.

Orthogonal radiography: it is recommended to use orthogonal radiographs as a minimum standard for cervical brachytherapy imaging for planning after every application. This allows evaluation of applicator geometry and some basic dosimetry parameters, in particular for the rectum/vagina and bladder.
Cross sectional imaging: cross sectional imaging to acquire 3D image data set for volumetric planning and dose recording should be performed whenever feasible.

MRI: MRI is the gold standard imaging for evaluation and BT planning during cervical cancer radiotherapy. Use of MRI during brachytherapy would help in accurate delineation of the target and organs and hence provide a higher degree of freedom for planning. Volumes related to target can be defined using T2W non-contrast MRI sequences (para-sagittal/sagittal, para-axial/axial and para-coronal/ coronal - fast spin echo or FSE sequence) that are acquired preferably with the applicator in situ. For better understanding of the protocol, GEC ESTRO working group recommendations or ICRU 89 should be followed [12,29].

CT: CT can be used for planning as an alternative to MRI. Use of the CT information, delineation of organs at risk and evaluation of OAR-based dose-volume histogram (DVH) parameters can be routinely done. However, tumor-related target delineation is a major challenge and remains an area of current research [30].

Also, there has been an increased interest in the use of low cost technology imaging such as ultrasonography for BT treatment planning. Further research and generation of robust data using US in BT planning are warranted $[31,32,33]$.

\section{Target and organs at risks definitions}

Historically, the target volume for BT boost reflected the gross disease at diagnosis including the whole uterus, which was mainly based on the Institut Gustav Roussy practice and experience. The concepts of target definition, prescription and planning of brachytherapy for cervical cancer have evolved over decades through various prescription and dosimetric systems across the world. The Manchester system-based point A (Figure 5) and volume-based prescription and planning developed by the GEC-ESTRO working group, detailed in ICRU 89, are the most widely accepted systems for target definition and planning currently.
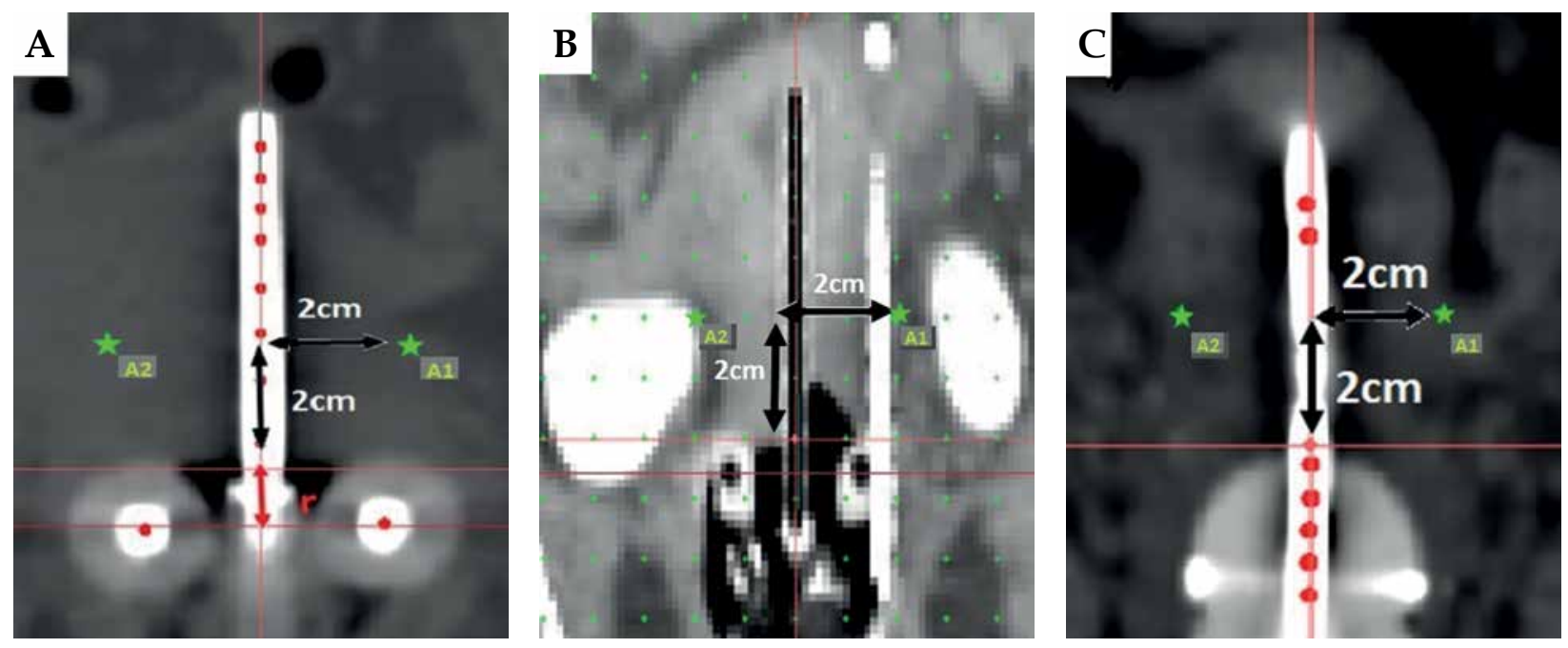

Fig. 5. Defining point A for tandem-ovoid (A), tandem-ring (B) and tandem-cylinder (C) applications (A1: left point A, A2: Right point A, $r=$ ovoid diameter) 


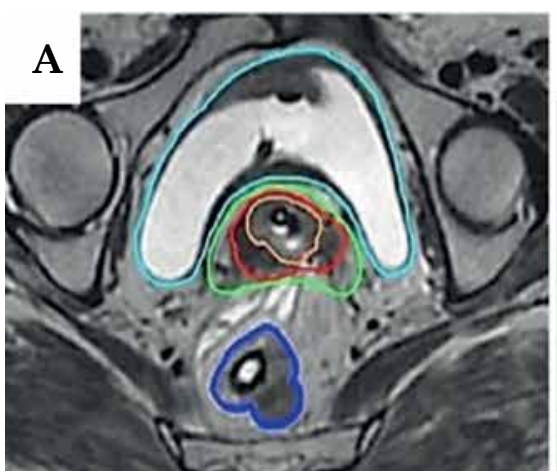

- Bladder

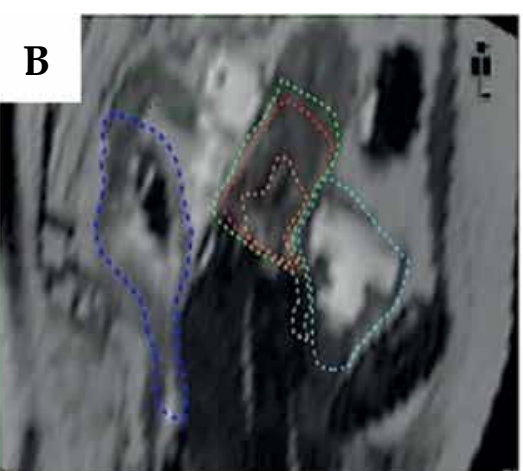

- $\mathrm{CTV}_{\mathrm{H}}$

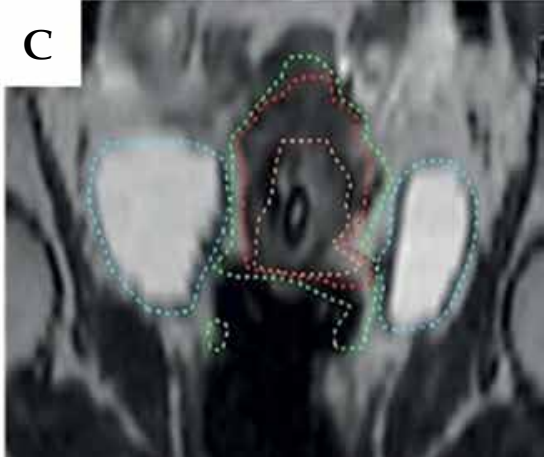

- Rectum

Fig. 6. Delineation of various structures on magnetic resonance images with applicator in situ. Gross tumor volume (orange), high risk clinical target volume (red), intermediate risk clinical target volume (green), bladder (cyan), rectum (blue) in axial (A), sagittal (B), and coronal (C) images can be noted

In orthogonal X-ray-based BT planning and point A prescription, there is no established surrogate for target; however, the NMDs when defined on radiographs may serve as the surrogate. ICRU bladder and recto-vaginal points are surrogates for bladder, rectum and vaginal doses.

In MR image-based planning, T2 weighted images are used to delineate the target and OARs (Figure 6). The delineation of the target should include the gross tumor volume at the time of brachytherapy $\left(\mathrm{GTV}_{\mathrm{B}}\right)$, high risk clinical target volume $\left(\mathrm{CTV}_{\mathrm{HR}}\right)$, intermediate risk clinical target volume $\left(\mathrm{CTV}_{\mathrm{IR}}\right)$ and bladder, rectum and sigmoid as OARs according to GEC-ESTRO/ICRU 89 recommendations. The outer wall of the organ is contoured routinely and based on this DVH parameters such as for $2 \mathrm{cc}$ for the rectum and bladder can be generated routinely, while extraction of the wall and DVH parameters are an area of research [10,11]. For the transition from conventional X-ray-based to 3D image-based brachytherapy, many institutes continue point A-based prescription on CT imaging and optimization is done for OARs, which is acceptable. In addition, NMDs may also be defined on either side of the tandem.

Target and normal tissue definitions are summarized in Table 2 [12]. The target at BT on MRI should be guided by clinical information of disease extent at diagnosis and BT and pretreatment MRI (MRI done before any treatment, i.e. before EBRT).

The target delineation in case of vault brachytherapy is less well defined and there is a need for further research on this subject. Currently, the target definition in such settings is guided by the information derived from clinical and imaging findings at the time of brachytherapy and guided by the implant geometry and catheters (needles/tubes).

\section{Applicator reconstruction}

Applicator reconstruction is the process of defining all the source channels on the brachytherapy planning images. Errors in applicator reconstruction can lead to geometric and dosimetric uncertainties [34]. Hence ap-

Table 2. Target and organs at risk definition in brachytherapy for cervical cancers (International Commission on Radiation Units and Measurements (ICRU) report no. 89 can be referred to for a detailed description)

\begin{tabular}{|c|c|c|}
\hline Imaging for planning & Defined target structures & Organs at risk \\
\hline Orthogonal radiographs & $\begin{array}{l}\text { Point A } \\
\text { Right and left near maximum distance points } \\
\text { if feasible }\end{array}$ & ICRU bladder and recto-vaginal points \\
\hline Computed tomography & $\begin{array}{l}\text { Point A } \\
\text { CTV } \\
\text { enced physician or in research setting) } \\
\text { Right and left near maximum distance points } \\
\text { encouraged for further research }\end{array}$ & $\begin{array}{l}\text { ICRU bladder and recto-vaginal points } \\
\text { Bladder, rectum, sigmoid, bowel contouring and } \\
\text { documentation of dose volume parameters } \\
\left(D_{0.1 \mathrm{~cm}^{3}}, D_{2 \mathrm{~cm}^{3}}\right)\end{array}$ \\
\hline Magnetic resonance imaging & $\begin{array}{l}\text { Point A } \\
\text { GTV }_{B} \\
\text { CTV }_{H R} \\
\text { CTV } \\
\text { Right and left near maximum distance points } \\
\text { related to CTV } \\
\text { HR for further research }\end{array}$ & $\begin{array}{l}\text { ICRU bladder and recto-vaginal points } \\
\text { Bladder, rectum, sigmoid and bowel contouring } \\
\text { and documentation of dose volume parameters } \\
\left(D_{\left.0.1 \mathrm{~cm}^{3}, D_{2 \mathrm{~cm}^{3}}\right)}\right.\end{array}$ \\
\hline
\end{tabular}


plicator commissioning is a prerequisite for minimizing errors during the applicator reconstruction process.

The applicator commissioning includes verification of the (i) applicator geometry using phantom scans or technical drawings, (ii) source path and dwell positions by autoradiography or imaging of the source inside the applicator.

Applicator commissioning is a prerequisite for a high level of accuracy in the applicator reconstruction process. The source positions are identified in relation to reference points within or in relation to the outer surface of the applicator. The applicator geometry and source channel can be assessed from phantom scans or from technical drawings of the applicator. Reconstruction of the applicator should be verified during applicator commissioning with which the source path and the outer dimensions of the applicator are verified in order to approve the applicator for clinical use. Applicator commissioning also includes an assessment and verification of selected dwell positions by autoradiography or imaging of the source inside the applicator (ICRU 89). The details of applicator commissioning are described in the GEC ESTRO recommendations $[12,35]$. A short summary is provided here.

The applicator reconstruction can be classified into two types:

1. Direct digitization when the source channels or marker wires are visible in the images.

2. Library-based digitization in which fixed-geometry applicators are merged with the patient images based on fusion of reference points or by direct positioning of the applicator shape into the images according to visible structures of the applicator, such as parts of the source path or the outer surface of the applicator.

For radiograph-based planning: Coded radiopaque markers placed in the source channel at the time of image acquisition ease the process of applicator reconstruction with acceptable accuracy. However, for ring applicators, orthogonal oblique images are preferred over anterolateral.

For CT-based planning: Visualization of the source channel without any markers is recommended while using CT images, as the contrast of the source channel and the outer surface of the applicator is adequate for direct digitization. Alternatively, it is also possible to insert markers in the source channels, which may be used as a guide during reconstruction; however, care must be taken that there are no artefacts, which may hinder the reconstruction process, because e.g. the markers for radiograph-based planning produce strong artefacts and hence should be avoided during CT image-based planning.

For MR image-based planning: Neither the source channel nor the applicator outer surface produces any signal on MRI images. Hence, special MR markers are used which produce an MR signal when inserted in the source channels during imaging. These markers are generally plastic catheters filled with water/copper sulfate which are available commercially. Apart from verification of the source path and dwell position during commissioning, susceptibility image artefacts created by tip of the applicator/ titanium/plastic tube should be characterized for the MR scanner used for MR image-based BT planning [29,35,36].

\section{Source loading patterns, planning and optimization}

The standard loading pattern for uterine and vaginal sources is essentially derived from radium loading of the Manchester system, which is the most commonly accepted system with vast clinical experience for cervical brachytherapy worldwide. With the advent of miniature sources ( $\left.{ }^{192} \mathrm{Ir}\right)$, after loading techniques and stepping source technology, the source loading can be simulated to that of radium loading used in the Manchester system so as to achieve a standard pear-shaped distribution. An example of loading patterns for standard intracavitary BT application (tandem-ovoids/ring) commonly used is given in Table 3.

Orthogonal X-ray-based ICBT planning: This includes standard loading patterns, normalization of the dose to point A to achieve a standard pear-shaped distribution, and evaluation of doses to ICRU recto-vaginal and bladder points. Doses delivered at NMDs, which represent a near minimum dose on either side, may also be documented. Manual optimization of the dwell time and dwell positions without major variations may be acceptable. Re-application should be considered in case of unacceptable geometry [12].

CT-based ICBT planning: The principles of loading and planning remain similar to orthogonal X-ray-based ICBT planning. Additionally, manual optimization to improve DVH parameters to OARs may be performed. Extreme care is needed during optimization, and deviation from standard loading and pear shape of dose distribution should be as minimal as possible. Optimization should not compensate for poor applicator geometry. Re-application should be considered in case of unacceptable geometry.

MR/CT image-based ICBT/ICIS planning: The planning is initiated with standard ICBT loading, normalization to point A, optimization to reduce doses to OARs and evaluation of doses to $\mathrm{CTV}_{\mathrm{HR}}$. Deviation from standard intracavitary loading should be minimal and doses to point A seldom less than $80 \%$ of the desired prescription. For ICIS applications, adequate DVH parameters with standard ICBT planning should be achieved; subsequently, the source positions in the needles/tubes should be activated in relation to the target $\left(\mathrm{CTV}_{\mathrm{HR}}\right)$ and care should be taken not to load in the region of the vaginal mucosa (at least $5 \mathrm{~mm}$ beyond). Also, the dwell time in the needles should be in the range of $10-20 \%$ and definitely not beyond $25 \%$ of the loading in the tandem or ovoid/ring.

Plan evaluation and documentation of various DVH parameters should be based on GEC ESTRO/ICRU 89 recommendations.

Interstitial BT planning: CT imaging is usually performed for template-based interstitial BT planning. However, MRI-based planning may be performed if an MR-compatible applicator is used. The BT planning is primarily based on basic Paris system rules [37] for interstitial BT including defining basal dose (BD) points, normalization to these points and prescription to the reference isodose (e.g. $85 \%$ or $90 \%$ isodose). However, with the use of a stepping source dosimetry system, the plan is further optimized using geometric followed by manual optimization. Graphical and volume-based optimizations 
Table 3. Example of standard loading pattern in tandem/ovoid and tandem/ring applicator Tandem and ovoid applicator Active dwell positions (2.5 $\mathrm{mm}$ spacing)

\begin{tabular}{|c|c|c|c|c|c|c|c|c|c|}
\hline \multirow{2}{*}{$\begin{array}{l}\text { Ovoid } \\
\text { nominal } \\
\text { diameter }\end{array}$} & 1.5 and $2 \mathrm{~cm}$ & 4 & 5 & 6 & - & - & - & - & - \\
\hline & 2.5 and $3 \mathrm{~cm}$ & 4 & 5 & 6 & 7 & - & - & - & - \\
\hline \multirow{3}{*}{$\begin{array}{l}\text { Tandem } \\
\text { length }\end{array}$} & $4 \mathrm{~cm}$ & 1 & 3 & 5 & 7 & 10 & 13 & - & - \\
\hline & $5 \mathrm{~cm}$ & 1 & 3 & 5 & 7 & 10 & 13 & 16 & - \\
\hline & $6 \mathrm{~cm}$ & 1 & 3 & 5 & 7 & 10 & 13 & 16 & 20 \\
\hline \multicolumn{2}{|c|}{ Tandem and ring applicator } & \multicolumn{8}{|c|}{ Active dwell positions ( $2.5 \mathrm{~mm}$ spacing) } \\
\hline \multirow{3}{*}{$\begin{array}{l}\text { Ring } \\
\text { nominal } \\
\text { diameter }\end{array}$} & $26 \mathrm{~mm}$ & 4 & 6 & 8 & 10 & 21 & 23 & 25 & 27 \\
\hline & $30 \mathrm{~mm}$ & 5 & 7 & 9 & 11 & 24 & 26 & 28 & 30 \\
\hline & $34 \mathrm{~mm}$ & 7 & 9 & 11 & 13 & 28 & 30 & 32 & 34 \\
\hline \multirow{3}{*}{$\begin{array}{l}\text { Tandem } \\
\text { length }\end{array}$} & $20 \mathrm{~mm}^{\star}$ & 1 & 4 & - & - & - & - & - & - \\
\hline & $40 \mathrm{~mm}$ & 1 & 3 & 5 & 7 & 10 & 13 & $16^{\#}$ & - \\
\hline & $60 \mathrm{~mm}$ & 1 & 3 & 5 & 7 & 10 & 13 & 16 & 20 \\
\hline
\end{tabular}

*If the tandem length is $20 \mathrm{~mm}$, then the ring dwell weights are decreased by $30 \%$;

are not recommended. If performed, it should be done by an experienced team only.

\section{Radiation therapy dose prescription}

The prescription depends on the EBRT and BT schedules. The combined EBRT and brachytherapy dose is generally expressed in terms of equivalent dose at $2 \mathrm{~Gy}$ per fraction $\left(\mathrm{EQD}_{2}\right)$ assuming $\alpha / \beta$ of $10 \mathrm{~Gy}$ for tumor and 3 Gy for OARs. The dose effect curves to achieve optimum local control rates and late effects are evolving.

Currently, a minimum dose of 75 Gy (range: 75-85 Gy) $\mathrm{EQD}_{2}$ to point A depending on the stage, or a minimum dose of 85 Gy (range: 85-90 Gy) $\mathrm{EQD}_{2}$ to target $\left(\mathrm{CTV}_{\mathrm{HR}}\right.$ $\mathrm{D}_{90}$ ) should be delivered [38]. A balance between the target and OAR doses should be made depending on the stage and residual disease at BT. In patients with extensive residual disease, the OAR doses may be compromised to achieve better target doses while reduction in OAR doses may be attempted in patients with no residual disease. Recent literature suggests that the dose constraints (measured as $\mathrm{EQD}_{2}$ ) for the ICRU bladder point and ICRU recto-vaginal point (previously known as ICRU rectal point) are $95 \mathrm{~Gy}$ and 65-70 Gy, respectively. Similarly, in 3D planning $2 \mathrm{~cm}^{3}$ doses for bladder and rectum should be restricted to less than $95 \mathrm{~Gy}$ and $75 \mathrm{~Gy}$, respectively $[39,40]$.

Various HDR fractionation regimens have been used for cervical cancer brachytherapy which range from 5 to 9 Gy per fraction prescribed at either point $A$ or to the $\mathrm{CTV}_{\mathrm{HR}}\left(\mathrm{D}_{90}\right)$ at 1-2 fractions every week for a total of 2-6 fractions to achieve the planning aim of external radiotherapy and brachytherapy [41]. It is recommended to limit the dose per fraction to less than or equal to $7 \mathrm{~Gy}$. Higher doses (up to $9 \mathrm{~Gy}$ ) per fraction or more frequent (not more than 2 applications per week) [42] may be used to respect the overall treatment time (OTT) of less than 56 days.

Overall treatment time for the combination of EBRT \pm concurrent $\mathrm{CT}$ and fractionated HDR BT should not exceed 8 weeks.

When an interstitial template is used for delivering boost doses, the most commonly used dose prescription is 4 Gy per fraction for 4-6 fractions (16-24 Gy) prescribed to the reference isodose volume depending on residual disease burden, OARs' doses and institutional practice $[25,43]$.

\section{Reporting}

BT prescription reporting should be as per ICRU 89 recommendations. Minimum standards (level 1) for reporting are detailed in Table 4 [12]. Although level 1 reporting is recommended as a minimum standard of reporting, it is encouraged to report advanced reporting parameters as described in the ICRU 89 report. In addition to ICRU 89 recommendations, reporting of near minimum dose to near maximum distances (right and left) is encouraged for further research.

Brachytherapy procedure related complications:

1. Perforation: Perforation during BT is commonly seen as a false passage through the fornices, missing the uterine canal or perforation through the wall of the uterus or cavity. These are often missed on orthogonal X-ray-based planning imaging, and reported literature suggests up to $15 \%$ perforation rates [22]. These can be prevented by the use of real-time ultrasonography (transabdominal US) intra-operatively during the BT procedure. The perforations can also be identified on cross sectional imaging done for BT planning. In cases of perforations through the fornices or anterior/ posterior walls of the uterus, the BT should be abandoned and a procedure under US guidance is recom- 
Table 4. Recommended reporting parameters in cervical cancer brachytherapy

\begin{tabular}{l} 
1. FIGO/TNM stage \\
\hline 2. Baseline morbidity and QoL assessment \\
\hline 3. Schematic 3D documentation on a clinical diagram indicat- \\
ing dimensions (width, thickness, height) for: \\
\hline - GTV at diagnosis \\
\hline - GTV at brachytherapy \\
\hline - CTV $V_{\text {HR }}$ \\
\hline - CTV $V_{\mathbb{R}}$ \\
\hline 4. Near maximum distance (NMD): left and right \\
\hline - TRAK
\end{tabular}

- Point A doses: left and right

- Recto-vaginal reference-point dose

- Bladder reference-point dose

- Near minimum doses to NMD: left and right

- $\mathrm{D}_{50}, \mathrm{D}_{90}, \mathrm{D}_{98}$ for CTV $\mathrm{HR}_{\mathrm{H}}$ and CTV $\mathrm{IR}$

- $\mathrm{D}_{0.1 \mathrm{~cm} 3}$ and $\mathrm{D}_{2 \mathrm{~cm} 3}$ for the bladder, rectum and sigmoid (if volumetric imaging done)

5. Dose delivery pattern
- Absorbed-dose rate/dose per fraction
- Number of fractions
- Time between fractions
- Overall treatment time
- Total EQD

6. Source and dose calculation

- Radionuclide and source model

- Source strength

- Dose-calculation algorithm

mended. In cases where tandem perforation occurs through the uterine cavity and fundus, brachytherapy could be delivered by avoiding source loading at the top of the tandem. These patients should undergo close monitoring including abdominal girth charting and treated with a course of antibiotics.

2. Bleeding: Bleeding from the tumor or procedure-related injury is encountered during the procedure or removal of the BT application. In the majority of situations, the bleeding can be arrested with conservative management including vaginal gauze packing and antifibrinolytics (tranexamic acid). If there is considerable blood loss, replacement is done by blood transfusions. If the bleeding is due to a vaginal tear, repair by suturing should be done under anesthesia.
3. Vaginal injuries: Vaginal injuries in the form of mucosal abrasions and tears related to the procedure may be seen. The treatment includes repair of the tear by suturing, avoiding BT treatments for 7-10 days and antibiotic therapy.

4. Bladder/rectal/bowel injuries: These are very rare and may require specialist surgeon care.

5. There is a lack of clinical data on brachytherapy-related complications and their management and there is a need for further research on this subject.

\section{Follow-up}

After the completion of planned therapy, response evaluation is usually done after 3-4 months. Patients with residual disease at the $1^{\text {st }}$ follow-up undergo close follow-up over the next 2-3 months. Patients with a complete response are reviewed every 3-4 monthly for the first 2 years and 6 monthly until at least 5 years and annually thereafter. Follow-up evaluation includes general and pelvic examination, imaging when indicated and investigations to document and manage late toxicities if any. Further research to generate data to establish the ideal method and frequency for follow-up is encouraged. Patients with recurrent disease usually need histological verification and treatment offered depending on the patient's general condition and the patterns of relapse.

In conclusion, brachytherapy is an integral part of treatment for cervical cancers. With an aim to reduce the heterogeneity in radiotherapy practices, we present here a comprehensive guide on cervical cancer radiotherapy with special emphasis on high dose rate brachytherapy. The report is based on high quality evidence and consensus opinion from national experts involved in treatment of cervical cancers.

\section{Acknowledgements}

We would like to acknowledge and sincerely thank Professor (em) Dr. Richard Pötter, Medical University of Vienna, for his independent review, discussion and inputs provided.

\section{Disclosure}

Authors report no conflict of interest.

\section{References}

1. Bray F, Ferlay J, Soerjomataram I et al. Global cancer statistics 2018: GLOBOCAN estimates of incidence and mortality worldwide for 36 cancers in 185 countries. CA Cancer J Clin 2018; 68: 394-424.

2. Sreedevi A, Javed R, Dinesh A. Epidemiology of cervical cancer with special focus on India. Int J Womens Health 2015; 7: 405-414.

3. Reducing uncertainties about the effects of chemoradiotherapy for cervical cancer: individual patient data meta-analysis. Cochrane Database Syst Rev 2010; (1): CD008285.

4. Viswanathan A, Thomadsen B. American Brachytherapy Society consensus guidelines for locally advanced carcinoma of the cervix. Part I: General principles. Brachytherapy 2012; 11: $33-46$. 
5. Cibula D, Pötter R, Planchamp F et al. The European Society of Gynaecological Oncology/European Society for Radiotherapy and Oncology/European Society of Pathology guidelines for the management of patients with cervical cancer. Radiother Oncol 2018; 127: 404-416.

6. Grover S, Gudi S, Gandhi A et al. Radiation Oncology in India: challenges and opportunities. Semin Radiat Oncol 2017; 27: 158-163.

7. Shrivastava S, Mahantshetty U, Engineer R et al. Treatment and outcome in cancer cervix patients treated between 1979 and 1994: a single institutional experience. J Cancer Res Ther 2013; 9: 672-679.

8. Nandakumar A, Kishor Rath G, Chandra Kataki A et al. Concurrent chemoradiation for cancer of the cervix: results of a multi-institutional study from the setting of a developing country (India). J Glob Oncol 2015; 1: 11-22.

9. Banerjee S, Mahantshetty U, Shrivastava S. Brachytherapy in India - a long road ahead. J Contemp Brachytherapy 2014; 6: 331-335.

10. Haie-Meder C, Pötter R, Van Limbergen E et al. Recommendations from Gynaecological (GYN) GEC-ESTRO Working Group (I): Concepts and terms in 3D image based 3D treatment planning in cervix cancer brachytherapy with emphasis on MRI assessment of GTV and CTV. Radiother Oncol 2005; 74: 235-245.

11. Pötter R, Haie-Meder C, Van Limbergen E et al. Recommendations from gynaecological (GYN) GEC ESTRO working group (II): Concepts and terms in 3D image-based treatment planning in cervix cancer brachytherapy - 3D dose volume parameters and aspects of 3D image-based anatomy, radiation physics, radiobiology. Radiother Oncol 2006; 78: 67-77.

12. Report 89. J ICRU 2013; 13: NP.

13. Kidd EA, Siegel BA, Dehdashti F et al. Lymph node staging by positron emission tomography in cervical cancer: relationship to prognosis. J Clin Oncol 2010; 28: 2108-2113.

14. Nugent E, Case A, Hoff J et al. Chemoradiation in locally advanced cervical carcinoma: An analysis of cisplatin dosing and other clinical prognostic factors. Gynecol Oncol 2010; 116 438-441.

15. Hanks G, Herring D, Kramer S. Patterns of care outcome studies results of the national practice in cancer of the cervix. Cancer 1983; 51: 959-967.

16. Lanciano R, Won M, Coia L et al. Pretreatment and treatment factors associated with improved outcome in squamous cell carcinoma of the uterine cervix: A final report of the 1973 and 1978 patterns of care studies. Int J Radiat Oncol Biol Phys 1991; 20: 667-676.

17. Han K, Milosevic M, Fyles A et al. Trends in the utilization of brachytherapy in cervical cancer in the United States. Int I Radiat Oncol Biol Phys 2013; 87: 111-119.

18. Farge D, Bounameaux $\mathrm{H}$, Brenner $\mathrm{B}$ et al. International clinical practice guidelines including guidance for direct oral anticoagulants in the treatment and prophylaxis of venous thromboembolism in patients with cancer. Lancet Oncol 2016; 17: e452-466.

19. Smith M, Todd J, Symonds R. Analgesia for pelvic brachytherapy. Br J Anaesth 2002; 88: 270-276.

20. Petereit D, Sarkaria J, Chappell R. Perioperative morbidity and mortality of high-dose-rate gynecologic brachytherapy. Int J Radiat Oncol Biol Phys 1998; 42: 1025-1031.

21. Tan P, Koh V, Tang J. Outpatient combined intracavitary and interstitial cervical brachytherapy: Barriers and solutions to implementation of a successful programme - a single institutional experience. J Contemp Brachytherapy 2015; 7: 259-263.

22. Segedin B, Gugic J, Petric P. Uterine perforation - 5-year experience in 3-D image guided gynaecological brachytherapy at Institute of Oncology Ljubljana. Radiol Oncol 2013; 47: $154-160$
23. Sharma V, Mahantshetty U, Menon V et al. A modified technique for high-dose-rate intracavitary brachytherapy in advanced cancer of the cervix. Brachytherapy 2003; 2: 246-248.

24. Kirisits C, Lang S, Dimopoulos J et al. The Vienna applicator for combined intracavitary and interstitial brachytherapy of cervical cancer: Design, application, treatment planning, and dosimetric results. Int J Radiat Oncol Biol Phys 2006; 65: 624-630.

25. Mahantshetty U, Shrivastava S, Kalyani N et al. Template-based high-dose-rate interstitial brachytherapy in gynecologic cancers: A single institutional experience. Brachytherapy 2014; 13: 337-342.

26. Rodriguez Villalba S, Richart Sancho J, Otal Palacin A et al. A new template for MRI-based intracavitary/interstitial gynecologic brachytherapy: design and clinical implementation. J Contemp Brachytherapy 2015; 7: 265-272.

27. Sturdza A, Potter R, Fokdal L et al. Image guided brachytherapy in locally advanced cervical cancer: Improved pelvic control and survival in RetroEMBRACE, a multicenter cohort study. Radiother Oncol 2016; 120: 428-433.

28. Mahantshetty U, Krishnatry R, Hande V et al. Magnetic resonance image guided adaptive brachytherapy in locally advanced cervical cancer: an experience from a tertiary cancer center in a low and middle income countries setting. Int $\mathrm{J} R a$ diat Oncol Biol Phys 2017; 99: 608-617.

29. Dimopoulos J, Petrow P, Tanderup K et al. Recommendations from Gynaecological (GYN) GEC-ESTRO Working Group (IV): Basic principles and parameters for MR imaging within the frame of image based adaptive cervix cancer brachytherapy. Radiother Oncol 2012; 103: 113-122.

30. Mahantshetty U, Naga Ch P, Khadanga C et al. A prospective comparison of computed tomography with transrectal ultrasonography assistance and magnetic resonance imaging-based target-volume definition during image guided adaptive brachytherapy for cervical cancers. Int J Radiat Oncol Biol Phys 2018; 102: 1448-1456.

31. Mahantshetty U, Khanna N, Swamidas J et al. Trans-abdominal ultrasound (US) and magnetic resonance imaging (MRI) correlation for conformal intracavitary brachytherapy in carcinoma of the uterine cervix. Radiother Oncol 2012; 102: 130-134.

32. Van Dyk S, Kondalsamy-Chennakesavan S, Schneider M et al. Comparison of measurements of the uterus and cervix obtained by magnetic resonance and transabdominal ultrasound imaging to identify the brachytherapy target in patients with cervix cancer. Int J Radiat Oncol Biol Phys 2014; 88: 860-865.

33. Nesvacil N, Schmid M, Pötter R et al. Combining transrectal ultrasound and CT for image-guided adaptive brachytherapy of cervical cancer: Proof of concept. Brachytherapy 2016; 15: 839-844.

34. Tanderup $K$, Hellebust $T$, Lang $S$ et al. Consequences of random and systematic reconstruction uncertainties in 3D image based brachytherapy in cervical cancer. Radiother Oncol 2008; 89: 156-163.

35. Hellebust T, Kirisits C, Berger D et al. Recommendations from Gynaecological (GYN) GEC-ESTRO working group: Considerations and pitfalls in commissioning and applicator reconstruction in 3D image-based treatment planning of cervix cancer brachytherapy. Radiother Oncol 2010; 96: 153-160.

36. Richart J, Carmona-Meseguer V, García-Martínez T et al. Review of strategies for MRI based reconstruction of endocavitary and interstitial applicators in brachytherapy of cervical cancer. Rep Pract Oncol Radiother 2018; 23: 547-561.

37. Pierquin B, Dutreix A, Paine $C$ et al. The Paris system in interstitial radiation therapy. Acta Radiol Oncol Radiat Ther Phys Biol 1978; 17: 33-48. 
38. Tanderup K, Fokdal L, Sturdza A et al. Effect of tumor dose, volume and overall treatment time on local control after radiochemotherapy including MRI guided brachytherapy of locally advanced cervical cancer. Radiother Oncol 2016; 120: 441-446.

39. Tan LT, Tanderup K, Kirisits $C$ et al. Image-guided adaptive radiotherapy in cervical cancer. Semin Radiat Oncol 2019; 29: 284-298.

40. Pötter R, Tanderup K, Kirisits C et al. The EMBRACE II study: The outcome and prospect of two decades of evolution within the GEC-ESTRO GYN working group and the EMBRACE studies. Clin Transl Radiat Oncol 2018; 9: 48-60.

41. Viswanathan A, Beriwal S, De Los Santos J et al. American Brachytherapy Society consensus guidelines for locally advanced carcinoma of the cervix. Part II: High-dose-rate brachytherapy. Brachytherapy 2012; 11: 47-52.

42. Patel F, Kumar P, Karunanidhi G et al. Optimization of high-dose-rate intracavitary brachytherapy schedule in the treatment of carcinoma of the cervix. Brachytherapy 2011; 10: 147-153.

43. Nandwani P, Vyas R, Neema J et al. Retrospective analysis of role of interstitial brachytherapy using template (MUPIT) in locally advanced gynecological malignancies. J Cancer Res Ther 2009; 3: 111-115. 